REIS JÚNIOR, R.A.; MONNERAT, P.H. Exportação de nutrientes nos tubérculos de batata em função de doses de sulfato de potássio. Horticultura Brasileira, Brasília, v. 19, n. 3, p. 227-231, novembro 2.001 .

\title{
Exportação de nutrientes nos tubérculos de batata em função de doses de sulfato de potássio*.
}

Roberto Anjos Reis Júnior ${ }^{1}$; Pedro Henrique Monnerat ${ }^{2}$

${ }^{1}$ Fundação Chapadão. C. Postal 39, 79.560-000 Chapadão do Sul-MS, email: reisjr@hotmail.com; ${ }^{2}$ UENF, 28.015-620 Campos dos

Goytacazes-RJ; Email: monnerat@uenf.br

\section{RESUMO}

A batata, importante olerícola no Brasil e no mundo, recebe altas doses de fertilizantes, especialmente potássicos. Dentre estes, o sulfato de potássio destaca-se devido ao conceito de que sua utilização melhora a qualidade dos tubérculos. Os fertilizantes representam um significativo percentual dos custos de produção desta cultura. Logo, o uso eficiente dos adubos deve ser alcançado para garantir competitividade do bataticultor no mercado. A avaliação das quantidades de nutrientes extraídas e exportadas pelos tubérculos durante o ciclo de desenvolvimento é uma ferramenta útil para otimizar o uso de fertilizantes. Para avaliar a extração e exportação de nutrientes nos tubérculos de batata, em função de doses de sulfato de potássio, foram aplicados $0 ; 125 ; 250$; 500; 1000 e $2000 \mathrm{~kg} \mathrm{ha}^{-1}$ de $\mathrm{K}_{2} \mathrm{SO}_{4}$ no sulco de plantio, em Viçosa (MG). Para avaliar os teores e as exportações de N, P, K, Ca, Mg, S, Cl, $\mathrm{Mn}$ e Zn nos tubérculos, duas plantas/parcela foram amostradas aos 20 dias após a emergência das plantas (DAE), aos 48 DAE e na colheita. O experimento foi analisado como fatorial $6 \times 3$, com seis doses de $\mathrm{K}_{2} \mathrm{SO}_{4}$ e três épocas de amostragem, delineado em blocos ao acaso, com quatro repetições. A adubação com sulfato de potássio promoveu acréscimos nos teores de $\mathrm{Cl}, \mathrm{Mn}$ e $\mathrm{Zn}$ nos tubérculos. As exportações de $\mathrm{K}, \mathrm{Ca}$, $\mathrm{Mg}, \mathrm{S}, \mathrm{Mn}$ e $\mathrm{Cl}$ aumentaram em resposta às doses de sulfato de potássio, somente na colheita. Na máxima produtividade de tubérculos $(30,5$ $\mathrm{Mg} \mathrm{ha}^{-1}$, com $\left.736 \mathrm{~kg} \mathrm{ha}^{-1} \mathrm{de} \mathrm{K}_{2} \mathrm{SO}_{4}\right)$, foram estimadas as seguintes exportações, em kg ha' ${ }^{-1}$ N $(99,1) ; \mathrm{P}(14,2) ; \mathrm{K}(118,5) ; \mathrm{Ca}(2,10) ; \mathrm{Mg}$ $(6,50) ; \mathrm{S}(9,28) ; \mathrm{Cl}(8,18) ; \mathrm{Mn}(0,048)$ e $\mathrm{Zn}(0,102)$. A exportação de nutrientes nos tubérculos representa importante perda de nutrientes do solo e sua avaliação, a princípio, deve ser utilizada para calibrar a recomendação de fertilizantes.

Palavras-chave: Solanum tuberosum L., adubação potássica, macronutriente, micronutriente.

\begin{abstract}
Nutrient removal by potato tubers in response to potassium sulphate applications.

Removal of nutrients by potato tubers was evaluated in response to the application of potassium sulphate to potato crops. Potassium was applied at six different rates $(0 ; 60 ; 120 ; 240 ; 480$ and $960 \mathrm{~kg}$ $\mathrm{ha}^{-1}$ of $\mathrm{K}_{2} \mathrm{O}$ ), as $\mathrm{K}_{2} \mathrm{SO}_{4}$ and placed during planting time in the furrow. Two plants/plot were sampled 20 days after plant emergence (DAE), $48 \mathrm{DAE}$ and at harvest to evaluate $\mathrm{N}, \mathrm{P}, \mathrm{K}, \mathrm{Ca}, \mathrm{Mg}, \mathrm{S}, \mathrm{Cl}, \mathrm{Mn}$ and $\mathrm{Zn}$ contents and removal by the tubers. A factorial $(6 \times 3)$, with six $\mathrm{K}_{2} \mathrm{O}$ rates and three sampling times was set up in a randomized block design with four replications. The application of $\mathrm{K}_{2} \mathrm{SO}_{4}$ increased $\mathrm{Cl}, \mathrm{Mn}$ and $\mathrm{Zn}$ concentration in potato tuber. Increasing $\mathrm{K}_{2} \mathrm{SO}_{4}$ fertilization affected potato tuber removal of nutrients only at harvest, when the application of potassium fertilizer increased the removal of $\mathrm{K}, \mathrm{Ca}, \mathrm{Mg}, \mathrm{S}, \mathrm{Mn}$ and $\mathrm{Cl}$. At maximum tuber yield, nutrient removal were: $99.1 \mathrm{~kg} \mathrm{ha}^{-1} \mathrm{~N} ; 14.2 \mathrm{~kg} \mathrm{ha}^{-1} \mathrm{P} ; 118.5 \mathrm{~kg} \mathrm{ha}^{-1} \mathrm{~K} ; 2.10 \mathrm{~kg}$ $\mathrm{ha}^{-1} \mathrm{Ca} ; 6.50 \mathrm{~kg} \mathrm{ha}^{-1} \mathrm{Mg} ; 9.28 \mathrm{~kg} \mathrm{ha}^{-1} \mathrm{~S} ; 8.18 \mathrm{~kg} \mathrm{ha}^{-1} \mathrm{Cl} ; 47.8 \mathrm{~g} \mathrm{ha}^{-1}$ $\mathrm{Mn}$ and $102.5 \mathrm{~g} \mathrm{ha}^{-1} \mathrm{Zn}$. Nutrient removal by tubers represents an important source of nutrient loss from the soil, and its evaluation should be used to calibrate fertilizer recommendations.
\end{abstract}

Keywords: Solanum tuberosum L., potassium application, macronutrient, micronutrient.

(Aceito para publicação em 24 de setembro de 2.001)

\footnotetext{
* Trabalho apresentado no XXXVIII Congresso Brasileiro de Olericultura, Petrolina-PE, 1998
} 
A batata (Solanum tuberosum L.), importante constituinte da dieta alimentar e produto comercial de vários países é cultivada em cerca de 18 milhões de hectares no mundo, com uma produção superior a 301 milhões de toneladas (FAO, 2000). No Brasil, é uma importante cultura, sendo cultivada em mais de 152 mil hectares, com uma produção estimada de 2,58 milhões de toneladas (IBGE, 2000). A produtividade média do Brasil é de 16,9 t ha-1 (FAO, 2000), sendo que o Estado de Minas Gerais se destaca por apresentar as maiores produções (cerca de 864 mil toneladas) e produtividades $\left(21,9 \mathrm{t} \mathrm{ha}^{-1}\right)$ e ocupar a terceira posição em área (mais de 39 mil hectares) (FNP Consultoria \& Comércio, 1999).

A cultura da batata recebe altas doses de fertilizantes, dentre os quais se destacam os potássicos. Porém, altas doses de adubação, como aquelas normalmente utilizadas na agricultura moderna, são normalmente criticadas devido à preocupação com impactos ambientais (Eppendorfer \& Eggum, 1994). Por exemplo, a aplicação liberal de adubos e água de irrigação durante a condução da cultura da batata podem estar contribuindo para a contaminação do lençol freático (Joern \& Vitoshi, 1995).

O potássio é o nutriente absorvido em maior quantidade pela batateira (Perrenoud, 1993) sendo, particularmente, necessário para a translocação de açúcares, síntese de amido (Reis Jr \& Fontes, 1996) e portanto, para a obtenção de altas produções de tubérculos (Westermann et al., 1994b) de boa qualidade (Westermann et al., 1994a). Muitos produtores têm adotado o sulfato de potássio como fonte de $\mathrm{K}$, pois há o conceito de que a utilização de $\mathrm{K}_{2} \mathrm{SO}_{4}$ melhora a qualidade dos tubérculos (Campora, 1994).

Embora o potássio seja requerido em altas quantidades, seu uso excessivo na agricultura, com doses acima da necessária para o satisfatório crescimento e desenvolvimento das plantas, pode reduzir a produção de tubérculos, além de elevar os custos de produção e causar impactos ambientais. É interessante ressaltar que altas doses de adubação potássica elevam a condutividade elétrica e a relação $\mathrm{K}^{+} /\left(\mathrm{Ca}^{2+}+\mathrm{Mg}^{2+}\right)^{1 / 2}$ do solo, prejudicando a produção de tubérculos (Reis Jr et al., 1999).

Por serem utilizados em grandes quantidades na cultura da batata, os adubos representam um significativo percentual dos custos de produção desta cultura. Sendo assim, há a necessidade do desenvolvimento de estratégias de manejo de adubos para a cultura da batata, otimizando a eficiência do uso de fertilizantes (Joern \& Vitoshi, 1995) e evitando a aplicação de adubos em doses acima da necessária. Esta otimização pode ser obtida mediante o conhecimento da exportação de nutrientes nos tubérculos, pois trata-se de uma útil ferramenta para estimar a quantidade de fertilizantes que deve ser aplicada ao solo com vistas à obtenção de altas produções e, também, calibração das recomendações de adubação. Com isto, as perdas de nutrientes e a contaminação ambiental serão minimizadas.

Para avaliar a exportação de nutrientes nos tubérculos é necessário determinar, além da produção de matéria seca por unidade de área, a concentração de nutrientes neste órgão. Muitos trabalhos de pesquisa já foram realizados para determinação de teores de macronutrientes nos tubérculos, porém poucas informações estão disponíveis na literatura sobre os teores de micronutrientes nos tecidos vegetais da batateira (Walworth \& Muniz, 1993). Trabalhos avaliando o efeito de fertilizantes sobre a composição de tubérculos de batata citam que o teor de $\mathrm{Cl}$ encontra-se entre 0,9-5,6 $\mathrm{g} \mathrm{kg}^{-1}$ de matéria seca (Dunn \& Rost, 1948). Saffigna et al. (1977), avaliando o efeito da adubação nitrogenada e da irrigação na produção de batata (Russet Burbank), constataram que o teor de $\mathrm{Cl}$ estava na faixa de 2,0 - 3,9 $\mathrm{g} \mathrm{kg}^{-1}$ de matéria seca de tubérculos coletados na época de colheita, enquanto que Maier (1986) encontrou teores de $\mathrm{Cl}$ maiores $(4,3-9,9 \mathrm{~g}$ $\mathrm{kg}^{-1}$ de matéria seca) em tubérculos coletados na mesma época de amostragem. O que, possivelmente, foi uma conseqüência do alto teor de cloretos na água usada para irrigação. Segundo Walworth \& Muniz (1993), plantas de aparência normal e nutricionalmente supridas para obtenção de altas produtividades apresentam teor de $\mathrm{Cl}$, em tubérculos coletados na colheita, na faixa de $0,98-3,31 \mathrm{~g} \mathrm{~kg}^{-1}$ de matéria seca. Trabalhos avaliando a influência da adubação com cálcio na composição mineral de tubérculos coletados na época da colheita constataram que os teores de Mn e Zn na cultivar Russet Burbank foi de 11,3 e 17,0 $\mathrm{g} \mathrm{kg}^{-1}$ de matéria seca, respectivamente. Enquanto que, na cultivar Frontier, foi de 13,4 e 18,8 $\mathrm{g} \mathrm{kg}^{-1}$ de matéria seca, respectivamente (Clough, 1994).

$\mathrm{Na}$ literatura existem vários trabalhos sobre a exportação de nutrientes nos tubérculos de batata coletados na colheita. Neles, constatam-se variações expressivas nas quantidades exportadas de nutrientes. Contudo, salienta-se que a quantidade de nutrientes exportadas é dependente da produção de matéria seca de tubérculos e concentração de nutrientes na matéria seca dos tubérculos (Maier, 1986). Os tubérculos de batata removem do solo muito mais potássio que outros nutrientes. A exportação de potássio é normalmente $1,5 \mathrm{vez}$ a de nitrogênio e quatro a cinco vezes a de fósforo, enquanto que as exportações de magnésio, enxofre e cálcio são bem menores quando comparadas a de potássio, mas ainda significantes (Perrenoud, 1993).

A quantidade de nutrientes presente, tanto na parte aérea quanto nos tubérculos, fornecerá estimativas do requerimento nutricional para a cultura da batata (Dunn \& Rost, 1948). Desde que a parte área da batateira possa ser incorporada ao solo após a colheita dos tubérculos, a avaliação da exportação de nutrientes nos tubérculos torna-se ferramenta útil para calibrar as recomendações de adubos para a lavoura da batata.

O objetivo deste trabalho foi quantificar a remoção de nutrientes do solo pelos tubérculos de batata, em diferentes estádios de crescimento, sob doses crescentes de sulfato de potássio.

\section{MATERIAL E MÉTODOS}

O experimento de campo foi realizado em solo cujas análises granulométrica e química na camada de 0-20 cm de profundidade apresentaram as seguintes características: areia gros$\mathrm{sa}=280 \mathrm{~g} \mathrm{~kg}^{-1}$, areia fina $=150 \mathrm{~g} \mathrm{~kg}^{-1}$; 
Tabela 1. Médias de produção de matéria seca e teores de $\mathrm{Cl}$, Mn e Zn na matéria seca de tubérculos de batata amostrados aos 20 dias após a emergência das plantas (DAE), 48 DAE e na colheita. Viçosa, UFV, 1993.

\begin{tabular}{lcccc}
\hline $\begin{array}{c}\text { Época de } \\
\text { amostragem }\end{array}$ & $\begin{array}{c}\text { Produção de } \\
\text { matéria seca } \\
\text { (g planta-1) }\end{array}$ & $\begin{array}{c}\text { Teor de Cl } \\
(\mathbf{g} \text { kg-1) }\end{array}$ & $\begin{array}{c}\text { Teor de } \mathbf{M n} \\
\text { (mg kg-1) }\end{array}$ & $\begin{array}{c}\text { Teor de } \mathbf{Z n} \\
\text { (mg kg-1) }\end{array}$ \\
\hline 20 DAE & 21,8 & 1,75 & 8,79 & 20,7 \\
48 DAE & 98,5 & 1,53 & 8,59 & 14,9 \\
Colheita & 110,3 & 1,52 & 9,15 & 22,2 \\
\hline
\end{tabular}

silte $=30 \mathrm{~g} \mathrm{~kg}^{-1} ; \operatorname{argila}=540 \mathrm{~g} \mathrm{~kg}^{-1} ; \mathrm{pH}$ $\left(\mathrm{H}_{2} \mathrm{O}\right)=4,7 ; \mathrm{P}=4,16 \mathrm{mg} \mathrm{dm}^{-3} ; \mathrm{K}=53,8$ $\mathrm{mg} \mathrm{dm}{ }^{-3} ; \mathrm{Al}^{3+}=9,0 \mathrm{mmol}_{\mathrm{c}} \mathrm{dm}^{-3} ; \mathrm{Ca}^{2+}=$ $1,7 \mathrm{mmol}_{\mathrm{c}} \mathrm{dm}^{-3} ; \mathrm{Mg}^{2+}=0,8 \mathrm{mmol}_{\mathrm{c}} \mathrm{dm}^{-3}$; $\mathrm{H}+\mathrm{Al}^{3+}=56,0 \mathrm{mmol}_{\mathrm{c}} \mathrm{dm}^{-3}$. A calagem foi realizada segundo o método de neutralização do alumínio, conforme recomendação da Comissão de Fertilidade do Solo do Estado de Minas Gerais (1999), utilizando-se calcário dolomítico.

$\mathrm{O}$ experimento foi instalado como um fatorial $6 \times 3$ (seis doses de sulfato de potássio e três épocas de amostragem), delineado em blocos ao acaso, com quatro repetições. Sulfato de potássio foi aplicado nas doses de 0 ; 125; 250; 500; 1000 e $2000 \mathrm{~kg} \mathrm{ha}^{-1}$ no sulco de plantio, juntamente com a adubação recomendada por Fontes (1987). Tubérculos de duas plantas/parcela foram amostrados aos 20 dias após a emergência das plantas (DAE), 48 DAE e na colheita.

Batatas-semente da cultivar Baraka, com aproximadamente $80 \mathrm{~g}$, foram plantadas em 05/08/93, no espaçamento de $0,8 \times 0,3 \mathrm{~m}$ e em parcelas constituídas de quatro fileiras de doze plantas. As plantas úteis, vinte por parcela, foram aquelas das duas fileiras centrais, menos a primeira e a última de cada fileira. Antes da amontoa, dez DAE foi realizada adubação, em cobertura, com sulfato de amônio, segundo recomendação de Fontes (1987). O experimento foi conduzido de acordo com as práticas comerciais da região de Viçosa (MG), incluindo, quando necessário, uso de irrigação.

As amostras de tubérculos foram submetidas à secagem em estufa com circulação forçada de ar a $72^{\circ} \mathrm{C}$ por 72 horas, moídas, passadas em peneiras com abertura de malha de 20 mesh, e pesadas. Após digestão sulfúrica $(0,1 \mathrm{~g}$ material vegetal seco $+1,5 \mathrm{~mL}$ de $\mathrm{H}_{2} \mathrm{SO}_{4}$ $+1 \mathrm{~mL}$ de $\mathrm{H}_{2} \mathrm{O}_{2} 30 \% \mathrm{v} / \mathrm{v}$ ), as amostras foram analisadas para N-orgânico pelo método de Nessler (Jackson, 1965). Os teores de $\mathrm{N}-\mathrm{NO}_{3}$ foram determinados por espectrofotometria, no comprimento de onda $210 \mathrm{~nm}$ (Cawse, 1967) e de $\mathrm{Cl}$, por titulação com $\mathrm{AgNO}_{3}$, após extração em banho-maria $\left(45^{\circ} \mathrm{C}, 60\right.$ minutos). As amostras também foram analisadas para $\mathrm{P}$ colorimetricamente pelo método do molibdato, $\mathrm{K}$ por espectrofotometria atômica de emissão de chama, S por turbidimetria e $\mathrm{Ca}, \mathrm{Mg}$, $\mathrm{Mn}$ e $\mathrm{Zn}$ por espectrofotometria de absorção atômica, após digestão da subamostra $(0,5 \mathrm{~g})$ com ácido nítrico $65 \%$ (4 mL) e ácido perclórico 70\% (2 $\mathrm{mL}$ ). Os teores de nutrientes descritos neste trabalho estão expressos com base na matéria seca de tubérculos.

A quantidade de nutrientes no tubérculo por planta foi determinada com base no teor dos nutrientes nos tubérculos e a produção de matéria seca total de tubérculos por planta. A quantidade de nutrientes nos tubérculos por hectare foi calculada mediante multiplicação da razão 10.000/0,24 pela quantidade de nutrientes nos tubérculos por planta.

Após o processo de senescência natural das plantas, procedeu-se à colheita do experimento.

Os dados obtidos foram submetidos às análises de variância e de regressão. Escolheu-se dentre os modelos linear, quadrático e base raiz quadrada, ajustados usando doses de potássio como variável independente, aquele que apresentasse lógica biológica, teste $\mathrm{F}$ da análise de variância da regressão estatisticamente significativos e de maior coeficiente de determinação. A dose de sulfato de potássio que proporcionou a maior produção de tubérculos foi introduzida no modelo ajustado de re- moção de nutrientes em função de doses de sulfato de potássio para determinar a remoção de nutrientes associada à máxima produção de tubérculos.

\section{RESULTADO E DISCUSSÃO}

As doses crescentes de sulfato de potássio aumentaram a produção de matéria fresca de tubérculos, alcançando valor máximo de $30,5 \mathrm{Mg} \mathrm{ha}^{-1}$ com a aplicação de $736 \mathrm{~kg} \mathrm{ha}^{-1}$ de $\mathrm{K}_{2} \mathrm{SO}_{4}$ (Fontes et al., 1996).

A adubação com $\mathrm{K}_{2} \mathrm{SO}_{4}$ não influenciou a produção de matéria seca de tubérculos e nem houve interação significativa entre doses de $\mathrm{K}_{2} \mathrm{SO}_{4}$ e época de amostragem. Por outro lado, a produção de matéria seca de tubérculo aumentou com o crescimento da planta $(p \leq 0,01)$ (Tabela 1), fato esse esperado. A produção de matéria seca de tubérculos na colheita $\left(4,6 \mathrm{Mg} \mathrm{ha}^{-1}\right)$ foi superior à encontrada por Dunn \& Rost (1948) (3,6 $\left.\mathrm{Mg} \mathrm{ha}^{-1}\right)$ e inferior à encontrada por Saffigna \& Keeney (1977) (13,7 Mg ha'-1). Estas diferenças entre as produções de matéria seca de tubérculos podem ser explicadas por diferenças entre condições edafo-climáticas, bem como cultivares, utilizadas por estes diferentes autores. Como houve aumento significativo de produção de matéria fresca de tubérculo, mas o mesmo não aconteceu com a produção de matéria seca de tubérculos, possivelmente, o aumento das doses de $\mathrm{K}_{2} \mathrm{SO}_{4}$ favoreceu o acúmulo de água nos tubérculos. Como o potássio não faz parte de estruturas celulares conhecidas, especula-se que o aumento do teor de $\mathrm{K}$ nos tecidos dos tubérculos (Reis Jr \& Monnerat, 1997) reduziu o potencial hídrico e favoreceu o acúmulo de água nestes tecidos.

A composição mineral dos tubérculos foi influenciada pela adubação com 
Tabela 2. Equações ajustada para teores de $\mathrm{Cl}, \mathrm{Mn}$ e $\mathrm{Zn}$, na matéria seca de tubérculos (y) em função de doses de sulfato de potássio (x), em kg ha-1. Viçosa, UFV, 1993.

\begin{tabular}{|c|c|}
\hline Nutriente & Equação \\
\hline $\mathrm{Cl}\left(\mathrm{g} \mathrm{kg}^{-1}\right)$ & $\mathrm{y}=1,21+1,97 \cdot 10^{-2} \sqrt{\mathrm{x}}-3,43 \cdot 10^{-5} \quad \mathrm{r}^{2}=0,93 * *$ \\
\hline $\operatorname{Mn}\left(\mathrm{mg} \mathrm{kg}^{-1}\right)$ & $y=7,67+0,104 \sqrt{x}-1,63 \cdot 10^{-3} \quad r^{2}=0,87$ * \\
\hline $\mathrm{Zn}\left(\mathrm{mg} \mathrm{kg}{ }^{-1}\right)$ & $y=18,0+1,95 \cdot 10^{-3} \quad r^{2}=0,84 * *$ \\
\hline
\end{tabular}

$\mathrm{K}_{2} \mathrm{SO}_{4}$, a qual promoveu aumentos nos teores de $\mathrm{N}$-nitrato, $\mathrm{K}$ e $\mathrm{Mg}$ nos tubérculos, mas não influenciou os teores de N-orgânico, P, Ca e S (Reis Jr \& Monnerat, 1997). A adubação com sulfato de potássio influenciou os teores de $\mathrm{Cl}(\mathrm{p} \leq 0,01), \mathrm{Mn}(\mathrm{p} \leq 0,05)$ e $\mathrm{Zn}(\mathrm{p} \leq 0,01)$, não havendo interação significativa com época de amostragem, enquanto que apenas os teores de $\mathrm{Cl}(\mathrm{p} \leq 0,05)$ e $\mathrm{Zn}$ $(\mathrm{p} \leq 0,01)$ foram diferentes entre as épocas de amostragem (Tabela 1). A adubação com $\mathrm{K}_{2} \mathrm{SO}_{4}$ aumentou o teor de $\mathrm{Cl}$ no tubérculo de $1,21 \mathrm{~g} \mathrm{~kg}^{-1}$, na testemunha, para 2,02 $\mathrm{g} \mathrm{kg}^{-1}$ com a aplicação de $2000 \mathrm{~kg} \mathrm{ha}^{-1}$ de $\mathrm{K}_{2} \mathrm{SO}_{4}$ (Tabela 2). O teor de Mn aumentou com as doses de sulfato de potássio, alcançando um valor máximo de $9,33 \mathrm{mg} \mathrm{kg}^{-1}$, com a aplicação de $1019 \mathrm{~kg} \mathrm{ha}^{-1}$ de $\mathrm{K}_{2} \mathrm{SO}_{4}$ (Tabela 2). O teor de $\mathrm{Zn}$ no tubérculo aumentou de $18,0 \mathrm{~g} \mathrm{~kg}^{-1}$, na testemunha, para $21,9 \mathrm{~g} \mathrm{~kg}^{-1}$ com a aplicação de 2000 $\mathrm{kg} \mathrm{ha}^{-1}$ de $\mathrm{K}_{2} \mathrm{SO}_{4}$ (Tabela 2). Na máxima estimativa da produtividade de tubérculos, os teores encontrados foram $1,72 \mathrm{~g} \mathrm{~kg}^{-1} \mathrm{de} \mathrm{Cl} ; 9,29 \mathrm{mg} \mathrm{kg}^{-1}$ de Mn e $19,4 \mathrm{mg} \mathrm{kg}^{-1}$ de $\mathrm{Zn}$. Tem sido reportado que os teores de $\mathrm{Cl}$, Mn e $\mathrm{Zn}$ na matéria seca de tubérculos, amostrados na colheita, estão na faixa de $0,9-5,9 \mathrm{~g} \mathrm{~kg}^{-1}$; $11,3-13,4 \mathrm{mg} \mathrm{kg}^{-1}$ e $17,0-18,0 \mathrm{mg} \mathrm{kg}^{-1}$, respectivamente (Dunn \& Rost,1948;
Saffigna et al., 1977; Walworth \& Muniz, 1993; Clough, 1994). Ao comparar esses valores com os teores obtidos para $\mathrm{Cl}$, Mn e Zn na máxima produtividade, constata-se que o teor de $\mathrm{Cl}$ esteve próximo ao limite inferior, o teor de Mn foi inferior e o teor de $\mathrm{Zn}$ superior aos teores encontrados na literatura. É possível que estas diferenças sejam conseqüências de diferentes práticas de adubação e irrigação e cultivares utilizadas.

A adubação com $\mathrm{K}_{2} \mathrm{SO}_{4}$ não influenciou a extração de nutrientes nos tubérculos aos 20 e 48 DAE, apresentando valores médios descritos na Tabela 3. Na colheita, a adubação com $\mathrm{K}_{2} \mathrm{SO}_{4}$ influenciou a exportação de $\mathrm{K}(\mathrm{p} \leq 0,01)$, $\mathrm{Ca}(\mathrm{p} \leq 0,05), \mathrm{Mg}(\mathrm{p} \leq 0,01), \mathrm{S}(\mathrm{p} \leq 0,01)$, $\mathrm{Mn}(\mathrm{p} \leq 0,05)$ e $\mathrm{Cl}(\mathrm{p} \leq 0,01)$, enquanto que as exportações médias de N-nitrato, N-orgânico, $\mathrm{P}$ e $\mathrm{Zn}$ foram de $12,3 \mathrm{~kg}$ $\mathrm{ha}^{-1} ; 86,8 \mathrm{~kg} \mathrm{ha}^{-1} ; 14,2 \mathrm{~kg} \mathrm{ha}^{-1}$ e $102,5 \mathrm{~g}$ ha $^{-1}$, respectivamente. A adubação com sulfato de potássio aumentou, na época da colheita, as exportações de $\mathrm{K}, \mathrm{Ca}$, $\mathrm{Mg}, \mathrm{S}, \mathrm{Cl}$ e Mn (Tabela 4). Na máxima produtividade, os tubérculos apresentaram, na colheita, exportações de 118,5 $\mathrm{kg} \mathrm{ha}^{-1}$ de K; $2,10 \mathrm{~kg} \mathrm{ha}^{-1}$ de Ca; $6,50 \mathrm{~kg}$ $\mathrm{ha}^{-1}$ de Mg; 9,28 $\mathrm{kg} \mathrm{ha}^{-1}$ de S; 8,18 kg ha $^{-1}$ de $\mathrm{Cl}$ e 47,8 $\mathrm{g} \mathrm{ha}^{-1}$ de Mn.

Possivelmente, aos 20 e 48 DAE a parte aérea foi o principal dreno para $\mathrm{K}$,
$\mathrm{Ca}, \mathrm{Mg}, \mathrm{S}, \mathrm{Cl}$ e $\mathrm{Mn}$, e apenas próximo à colheita, os tubérculos se tornaram o principal dreno para estes nutrientes. No caso do N, Lewis (1989) argumenta que cultivares de batata que absorvem grandes quantidades deste nutriente não $o$ convertem, necessariamente, em produção de tubérculos, indicando que altas doses de $\mathrm{N}$ estão mais relacionadas com o crescimento da parte aérea.

Comparando-se as exportações de alguns nutrientes citadas na literatura, constatam-se diferenças nas quantidades exportadas, as quais podem ser atribuídas à diferenças de produtividade, cultivar empregado e práticas culturais, por exemplo. No trabalho de Cunha et al. (1999), foram encontradas exportações de K e S similares e exportações de $\mathrm{Ca}$ e $\mathrm{Mg}$ bem superiores àquelas observadas no presente trabalho, com uma produtividade inferior.

Na máxima produção, as eficiências de absorção de nutrientes pelos tubérculos (percentagem do nutriente aplicado ao solo que é exportado no tubérculo) de N, P, K, Ca, Mg, S e Zn foram de $49,5 \% ; 6,0 \% ; 40,4 \% ; 0,3 \% ; 36,1 \%$; $1,2 \%$ e $3,4 \%$, respectivamente. Para aqueles nutrientes que apresentam perdas insignificantes no solo (nutrientes de baixa mobilidade, ou aqueles que não são perdidos por volatilização, erosão ou lixiviação), a baixa eficiência de absorção, sugere que a dose de nutriente a ser aplicada no cultivo subsequente da batateira poderá ser menor. Como a baixa eficiência de absorção está associada a um alto resíduo de nutriente no solo, cuidados devem ser tomados no sentido de evitar lixiviação de nutrientes e

Tabela 3 - Extração média de nutrientes nos tubérculos de batata amostrados aos 20 e 48 dias após a emergência das plantas (DAE). Viçosa, UFV, 1993.

\begin{tabular}{|c|c|c|c|c|c|}
\hline \multirow{2}{*}{ Nutriente } & \multicolumn{2}{|c|}{ Extração de nutriente (kg ha-1) } & \multirow{2}{*}{ Nutriente } & \multicolumn{2}{|c|}{ Extração de nutriente (g ha-1) } \\
\hline & 20 DAE & 48 DAE & & 20 DAE & 48 DAE \\
\hline N-nitrato & 2,40 & 10,9 & $\mathrm{Mn}$ & 7,59 & 34,8 \\
\hline N-orgânico & 20,1 & 73,6 & $\mathrm{Zn}$ & 18,3 & 60,4 \\
\hline$P$ & 3,11 & 11,7 & - & - & - \\
\hline K & 22,2 & 82,3 & - & - & - \\
\hline $\mathrm{Ca}$ & 0,54 & 1,28 & - & - & - \\
\hline $\mathrm{Mg}$ & 1,19 & 5,33 & - & - & - \\
\hline$S$ & 1,53 & 6,65 & - & - & - \\
\hline $\mathrm{Cl}$ & 1,53 & 6,20 & - & - & - \\
\hline
\end{tabular}


Tabela 4. Equações ajustada para exportações de $\mathrm{K}, \mathrm{Ca}, \mathrm{Mg}, \mathrm{S}, \mathrm{Cl}$ e $\mathrm{Mn}$ (y) em função de doses de sulfato de potássio (x), em kg hä ${ }^{-1}$ Viçosa, UFV, 1993.

\begin{tabular}{ll}
\hline \multicolumn{1}{c}{ Nutriente } & \multicolumn{1}{c}{ Equação } \\
\hline K (Kg ha-1) & $y=59,7+3,99 \sqrt{x}-6,72 \cdot 10^{-2} \quad r^{2}=0,92$ * * \\
Ca (Kg ha-1) & $y=1,51+5,98 \cdot 10^{-2} \sqrt{x}-1,40 \cdot 10^{-3} \quad r^{2}=0,97$ * \\
Mg (Kg ha-1) & $y=4,04+1,92 \cdot 10^{-1} \sqrt{x}-3,73 \cdot 10^{-3} \quad r^{2}=0,92$ * * \\
S (Kg ha-1) & $y=6,26+2,42 \cdot 10^{-1} \sqrt{x}-2,08 \cdot 10^{-2} \quad r^{2}=0,82$ * * \\
Cl (Kg ha- 1$)$ & $y=3,95+2,33 \cdot 10^{-1} \sqrt{x}-2,85 \cdot 10^{-3} \quad r^{2}=0,97$ * \\
Mn (g ha-1) & $y=31,7+1,29 \sqrt{x}-2,58 \cdot 10^{-2} \quad r^{2}=0,89$ * \\
\hline
\end{tabular}

contaminação de lençol freático.

A quantidade de nutriente exportada nos tubérculos representa importante componente de perdas de nutriente do solo (Maier, 1986) e sua avaliação deve ser utilizada para calibrar a recomendação de fertilizantes.

\section{AGRADECIMENTOS}

Ao Prof. Paulo C. R. Fontes. Ao laboratorista José Accácio da Silva pela colaboração nas análises químicas realizadas.

\section{LITERATURA CITADA}

CAMPORA, P.S. Importância da adubação na qualidade dos produtos agrícolas. São Paulo: Ícone, 1994. $373 \mathrm{p}$.

CAWSE, P.A. The determination of nitrate in soil solution by ultraviolet spectrophotometry. Analyst, v. 9, p. 309-313, 1967.

CLOUGH, G.H. Potato tuber yield, mineral concentration, and quality after calcium fertilization. Journal of American Horticultural Science, v. 119, p. 175-179, 1994.

COMISSÃO DE FERTILIDADE DO SOLO DO ESTADO DE MINAS GERAIS. Recomendação para o uso de corretivos e fertilizantes em Minas Gerais: 5a aprox. Viçosa: CFSEMG, 1999. 359 p.
CUNHA, A.O.; SOUZA, A.S.; SILVA, A.P.; SILVEIRA, R.R.; DANTAS, J.P. Extração e exportação de macronutrientes pela cultura da batata (Solanum tuberosum L.). In: CONGRESO BRASILEIRO DE CIÊNCIA DO SOLO, 27 , 1999, Brasília, DF. Resumos... Brasília: EMBRAPA/UNB. 1999 (CD-ROM)

DUNN, E.E.; ROST, C.O. Effect of fertilizers on the composition of potatoes grown in the Red River Valley of Minnesota. Soil Science Society Proceedings, v. 13, p. 374-379, 1948.

EPPENDORFER, W.H.; EGGUM, O. Effects of sulfur, phosphorus, potassium, and water stress on dietary fiber fractions, starch, amino acids and on the biological value of potato protein. Plant Foods for Human Nutrition, v. 45, p. 299-313, 1994.

FAO. FAO Database Gateway. http://www.fao.org em $12 / 11 / 2000$

FNP CONSULTORIA \& COMÉRCIO. Agrianual 99. São Paulo, 1999. p. 189.

FONTES, P.C.R. Nutrição mineral e adubação. In: REIFSHNEIDER, F.J.B. (Coord.) Produção de batata. Brasília: Linha Gráfica, 1987. p. 40-56.

FONTES, P.C.R.; REIS JR, R.A.; PEREIRA, P.R.G. Critical potassium concentration and potassium/calcium plus magnesium ratio in potato petioles associated with maximum tuber yields. Journal of Plant Nutrition, v. 19, p. 657-667, 1996

IBGE. Sistema de recuperação automática - SIDRA97. http://www.sidra.ibge.gov.br em 12/11/ 2000.

JACKSON, M.L. Soil chemical analysis. New Jersey: Prentice Hall, 1965. 498 p.
JOERN, B.C.; VITOSHI, M.L. Influence of applied nitrogen on potato. Part I: yield, quality and nitrogen uptake. American Potato Journal, v. 72, p. 51-63, 1995

LEWIS, R.J. Petiole nitrate profiles and N uptake: a comparison among seven potato cultivars. Aberdeen: Brigham Young University, 1989. 24 p. (Tese mestrado)

MAIER, N.A. Potassium nutrition of irrigated potatoes in South Australia: 2. Effect on chemical composition and the prediction of tuber yield response by plant analysis. Australian Journal of Experimental Agriculture, v. 26, p. 727-736, 1986. PERRENOUD, S. Potato: fertilizers for yield and quality. Bern: International Potash Institute, 1993. $94 \mathrm{p}$.

REIS JR, R.A.; FONTES, P.C.R. Qualidade de tubérculos da batateira em função de doses de adubação potássica. Horticultura Brasileira, Brasília, v. 14, p. 170-174, 1996.

REIS JR, R.A.; MONNERAT, P.H. Composição mineral de tubérculos de batata em função da adubação potássica: macronutrientes. Actas de Horticultura, v. 16, p. 355-362, 1997.

REIS JR, R.A.; FONTES, P.C.R.; NEVES, J.C.L; SANTOS, N.T. Total soil electrical conductivity and critical soil $\mathrm{K}^{+}$to $\mathrm{Ca}^{2+}$ and $\mathrm{Mg}^{2+}$ ratio for potato crops. Scientia Agricola, Piracicaba, v. 56, p. 985989, 1999.

SAFFIGNA, P.G.; KEENEY, D.R.; TANNER, C.B. Nitrogen, chloride, and water balance with irrigated Russet Burbank potatoes in a sandy soil. Agronomy Journal, v. 69, p. 251-263, 1977.

SAFFIGNA, P.G.; KEENEY. D.R. Nitrogen and chloride uptake by irrigated Russet Burbank potatoes. Agronomy Journal, v. 69, p. 258-263, 1977.

WALWORTH, J.L.; MUNIZ, J.E. A compendium of tissue nutrient concentrations for field-grown potatoes. American Potato Journal, v. 70, p. 579597, 1993.

WESTERMANN, D.T.; JAMES, D.W.; TINDALL, T.A.; HURST, T.R.L. Nitrogen and potassium fertilization of potatoes: sugars and starch. American Potato Journal, v. 71, p. 433454, 1994a.

WESTERMANN, D.T.; TINDALL, T.A.; JAMES, D.W.; HURST, T.R.L. Nitrogen and potassium fertilization of potatoes: yield and specific gravity. American Potato Journal, v. 71, p. 417-432, 1994b. 